\title{
Groundwater Quality in the Coastal Los Angeles Basin, California
}

Groundwater provides more than $\mathbf{4 0}$ percent of California's drinking water. To protect this vital resource, the State of California created the Groundwater Ambient Monitoring and Assessment (GAMA) Program. The Priority Basin Project of the GAMA Program provides a comprehensive assessment of the State's groundwater quality and increases public access to groundwater-quality information. The Coastal Los Angeles Basin constitutes one of the study units being evaluated.

\section{The Coastal Los Angeles Basin Study Unit}

The Coastal L os A ngeles Basin study unit is approximately 860 square miles and consists of the Santa M onica, Hollywood, West Coast, Central, and Orange County Coastal Plain groundwater basins (California D epartment of Water Resources, 2003). The basins are bounded in part by faults, including the New port-Inglewood fault zone, and are filled with Holocene-, Pleistocene-, and Pliocene-age marine and alluvial sediments. The Central Basin and Orange County Coastal Plain are divided into a forebay zone on the northeast and a pressure zone in the center and southwest. The forebays consist of unconsolidated coarser sediment, and the pres-

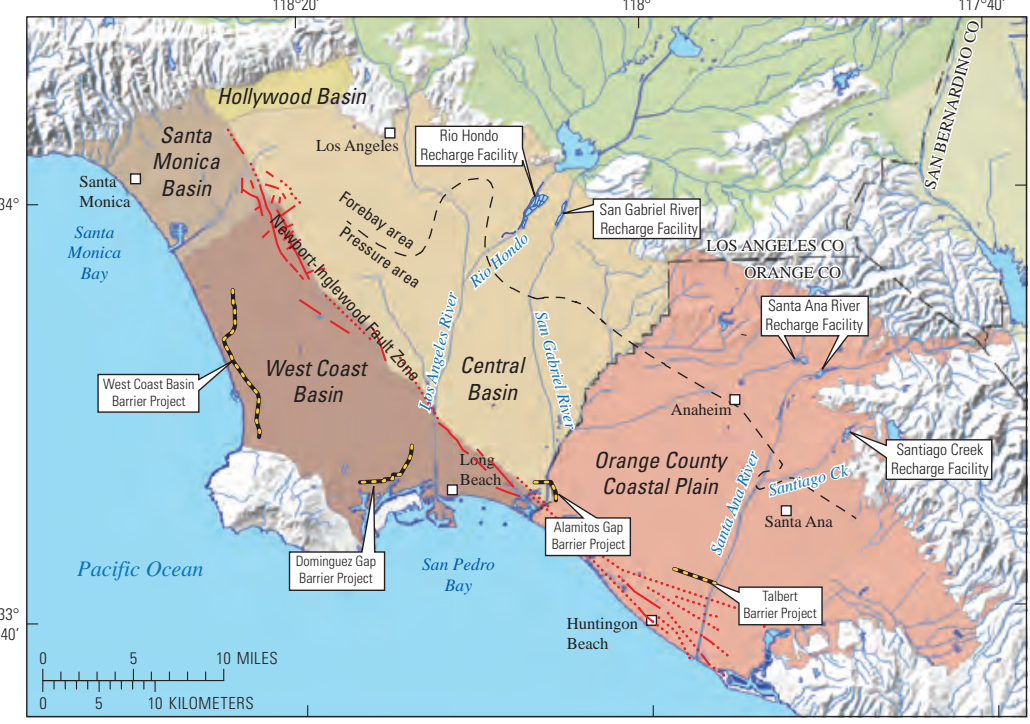

sure zones are characterized by lenses of coarser sediment divided into confined to semi-confined aquifers by lenses of finer sediments. The primary aquifer system in the study unit is defined as those parts of the aquifer system corresponding to the perforated intervals of wells listed

in the California Department of Public Health (CDPH) database of public-supply wells. The majority of public-supply wells are drilled to depths of 510 to 1,145 feet, consist of solid casing from the land surface to a depth of about 300 to 510 feet, and are perforated below the solid casing. Water quality in the primary aquifer system may differ from that in the shallower and deeper parts of the aquifer systems.

The study area has hot, dry summers and cool, moist winters. Average annual rainfall is about 15 inches. The L os A ngeles, San Gabriel, and Santa A na Rivers and the R io Hondo, with headwaters in the mountains to the north and east of the study unit, are the primary streams traversing the study unit. Land use in the study unit is about 86 percent (\%) urban, $12 \%$ natural, and $2 \%$ agricultural. $N$ atural lands include coastal ecological preserves. The urban landscape consists of residential, commercial, and industrial areas, and the large urban centers include the cities of L os A ngeles, L ong B each, A naheim, Santa A na, and Huntington B each.

Recharge to the Central Basin and Orange County Coastal Plain occurs primarily by engineered recharge of stormwater, imported water, and reclaimed water along the upper reaches of the San Gabriel and Santa A na Rivers and the Rio Hondo. Recharge to the West Coast B asin occurs primarily by injection of imported water and reclaimed water into wells of the seawater intrusion barrier and by underflow from the Central Basin. Groundwater flow directions are controlled by the engineered recharge and by groundwater pumping from the many hundreds of wells distributed across the region (Shelton and others, 2001; Daw son and others, 2003).

\section{Overview of Water Quality}
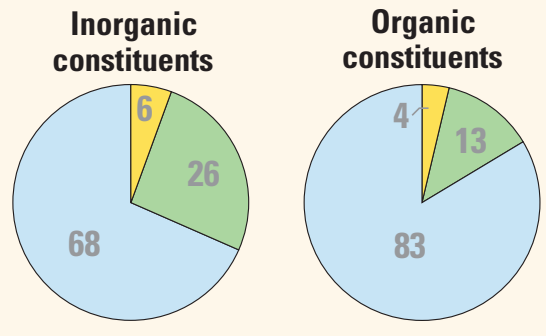

CONSTITUENT CONCENTRATIONS

$\bigcirc$ High $\bigcirc$ Moderate $\bigcirc$ Low or not detected

Values are a percentage of the area of the primary aquifer system with concentrations in the three specified categories.

GA M A's Priority Basin Project evaluates the quality of untreated groundwater. How ever, for context, benchmarks established for drinking-water quality are used for comparison. B enchmarks and definitions of high, moderate, and low concentrations are discussed in the blue section at the bottom of page 3 .

$M$ any inorganic constituents occur naturally in groundwater. The concentrations of the inorganic constituents can be affected by natural processes as well as by human activities. In the Coastal LoS A ngeles B asin study unit, one or more inorganic constituents were present at high concentrations in about $6 \%$ of the primary aquifer system and at moderate concentrations in about $26 \%$.

Human-made organic constituents are found in products used in the home, business, industry, and agriculture. Organic constituents can enter the environment through normal usage, spills, or improper disposal. In this study unit, one or more organic constituents were present at high concentrations in about $4 \%$ of the primary aquifer system and at moderate concentrations in about $13 \%$. 


\section{RESULTS: Groundwater Quality in the Coastal Los Angeles Basin Study Unit}

\section{INORGANIC CONSTITUENTS}
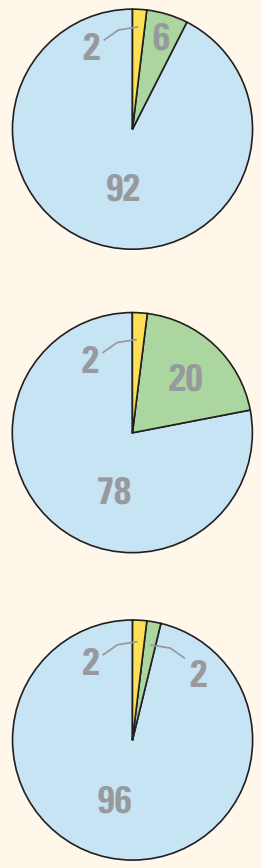

Uranium and radioactive constituents

\section{Nutrients}
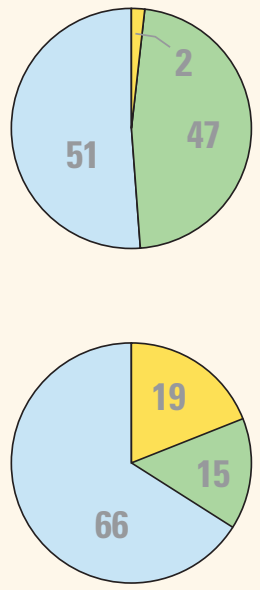

Iron or manganese
SPECIAL-INTEREST CONSTITUENT

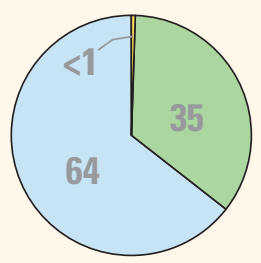

\section{Inorganic Constituents with Human-Health Benchmarks}

Trace and minor elements are naturally present in the minerals in rocks and soils, and in the water that comes into contact with those materials. In the Coastal L os A ngeles Basin study unit, trace elements were detected at high concentrations in about $2 \%$ of the primary aquifer system, and at moderate concentrations in about $6 \%$. A rsenic was the trace element that most frequently occurred at high and moderate concentrations.

R adioactivity is the rel ease of energy or energetic particles during spontaneous decay of unstable atoms. M ost of the radioactivity in groundwater comes from the decay of naturally occurring isotopes of uranium and thorium in minerals in the sediments of the aquifer. U ranium and gross al pha radioactivity occurred at high levels in about $2 \%$ of the primary aquifer system, and at moderate levels in about $20 \%$.

$\mathrm{N}$ utrients are naturally present at low concentrations in groundwater, and high and moderate concentrations generally occur as a result of human activities. Common sources of nutrients include fertilizer applied to crops and landscaping, seepage from septic systems, and human and animal waste. $N$ itrate was present at high concentrations in about $2 \%$ of the primary aquifer system, and at moderate concentrations in about $2 \%$.

\section{Inorganic Constituents with Non-Health Benchmarks}

(Not included in water-quality overview charts shown on the front page)

Some constituents affect the aesthetic properties of water, such as taste, color, and odor, or may create nuisance problems, such as staining and scaling. The State of California has a recommended and an upper limit for total dissolved solids (TDS) in drinking water. All groundwater naturally contains TDS as a result of the weathering and dissolution of minerals in sediments. A noxic conditions in groundwater (low amounts of dissolved oxygen) may result in release of manganese and iron from minerals into groundwater.

In the Coastal L os A ngeles B asin study unit, TDS concentrations were high (greater than the upper limit) in about $2 \%$ of the primary aquifer system, and moderate (between the recommended and upper limits) in about 47\%. I ron or manganese (or both) were present at high concentrations in about 19\% of the primary aquifer system, and at moderate concentrations in about $15 \%$.

\section{Special-Interest Constituents}

(Not included in water-quality overview charts shown on the front page)

Perchlorate is an inorganic constituent that has been regulated in California drinking water since 2007. It is an ingredient in rocket fuel, fireworks, and other products, may be present in some fertilizers, and occurs at low concentrations under natural conditions in groundwater. Perchlorate was detected at high concentrations in $<1 \%$ of the primary aquifer system and at moderate concentrations in about 35\%.

1,4-Dioxane is used as a stabilizer for solvents, and $\mathrm{N}$-nitrosodimethylamine (NDM A) is an ingredient in rocket fuel and may be formed as a byproduct of disinfection treatment. 1,4-Dioxane was detected at high and moderate concentrations in the primary aquifer system, and NDM A was detected at moderate concentrations; however, the number of samples was not great enough to provide a statistically representative estimate of proportions of the primary aquifer system with high or moderate concentrations. 


\section{RESULTS: Groundwater Quality in the Coastal Los Angeles Basin Study Unit}

\section{ORGANIC CONSTITUENTS}

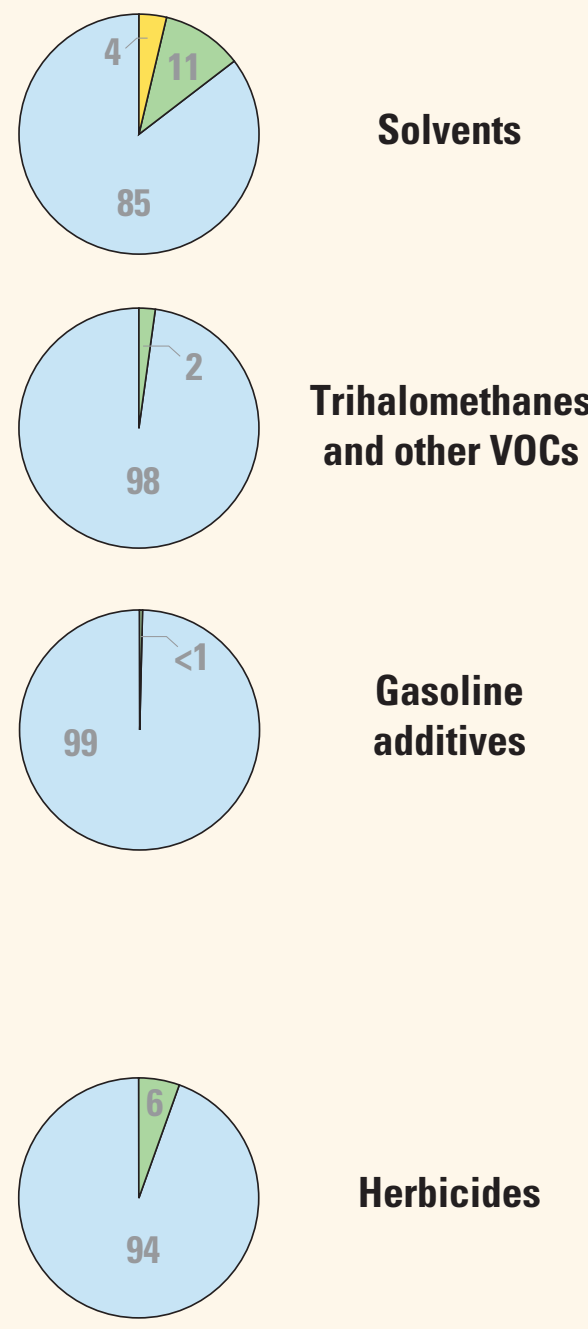

\section{Organic Constituents}

The Priority Basin Project uses laboratory methods that can detect low concentrations of volatile organic compounds (VOCs) and pesticides, far below human-health benchmarks. The presence of VOCs and pesticides detected at these low concentrations can be used to trace water from the landscape into the aquifer system.

\section{Volatile Organic Compounds with Human-Health Benchmarks}

VOCs are in many household, commercial, industrial, and agricultural products and are characterized by their tendency to volatilize (evaporate) into the air.

Solvents are used for a number of purposes, including manufacturing and cleaning. In the Coastal L os A ngeles B asin study unit, solvents were present at high concentrations in about $4 \%$ of the primary aquifer system, and at moderate concentrations in $11 \%$. The solvents detected at high concentrations were tetrachloroethene (PCE), trichloroethene (TCE), 1,1-dichloroethene, 1,2-dichloroethane, and carbon tetrachloride.

Trihalomethanes can form during disinfection of water supplies and may enter groundwater by the infiltration of landscape irrigation water or leakage of distribution systems. Trihal omethanes were not detected at high concentrations and were present at moderate concentrations in about $2 \%$ of the primary aquifer system.

Gasoline additives increase the efficiency of fuel combustion. Gasoline additives were not detected at high concentrations and were present at moderate concentrations in $<1 \%$ of the primary aquifer system.

Other V OCs, including organic synthesis reagents and refrigerants, were not detected at moderate or high concentrations.

\section{Pesticides with Human-Health Benchmarks}

Pesticides, including herbicides, insecticides, and fumigants, are applied to crops, gardens, lawns, around buildings, and along roads to help control unwanted vegetation (weeds), insects, fungi, and other pests. In the Coastal L os A ngeles B asin study unit, herbicides were not detected at high concentrations in the primary aquifer system, but were present at moderate concentrations in about $6 \%$. Insecticides and fumigants were not detected at high or moderate concentrations.

\section{BENCHMARKS FOR EVALUATING GROUNDWATER QUALITY}

GA M A's Priority Basin Project uses benchmarks established for drinking water to provide context for evaluating the quality of untreated groundwater. A fter withdrawal, groundwater may be disinfected, filtered, mixed, and exposed to the atmosphere before being delivered to consumers. Federal and $C$ alifornia regulatory benchmarks for protecting human heal th ( $M$ aximum Contaminant $L$ evel, $M C L$ ) are used when available. Otherwise, nonregulatory benchmarks for protecting aesthetic properties, such as taste and odor (Secondary M aximum Contaminant Level, SM CL), and nonregulatory benchmarks for protecting human health (Notification Level, NL, and Lifetime Health A dvisory, HAL) are used.

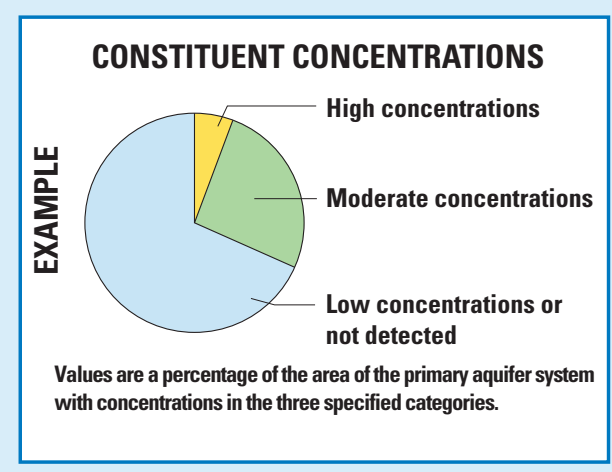

High, moderate, and low concentrations are defined relative to benchmarks

Concentrations are considered high if they are greater than a benchmark. For inorganic constituents, concentrations are moderate if they are greater than one-half of a benchmark. For organic and special-interest constituents, concentrations are moderate if they are greater than one-tenth of a benchmark; this lower threshold was used because organic constituents generally are less prevalent and have smaller concentrations relative to benchmarks than inorganic constituents. Low includes nondetections and values less than moderate concentrations. M ethods for evaluating water quality are discussed by Goldrath and others (2012). 


\section{Factors that Affect Groundwater Quality}

In the Coastal L os A ngeles B asin study unit, solvents were detected at high concentrations in about $4 \%$ of the primary aquifer system and at moderate concentrations in about $11 \%$. Solvents were detected in $42 \%$ of the grid wells sampled ( $G$ oldrath and others, 2012). PCE and TCE were the most frequently detected solvents. The map below shows the distribution of solvents in groundwater. Groundwater with high and moderate concentrations of solvents is most prevalent in the central and eastern parts of the Central Basin. Groundwater in the Central Basin moves radially and laterally from current and historical recharge areas al ong the river channels in the forebay areas (Shelton and others, 2001; Dawson and others, 2003). The occurrence of solvents in the groundwater is not correlated with current overlying land use and human activities. Rather, the solvents are from legacy industrial uses, and it has taken decades for the groundwater to move from the areas of recharge to the areas of the basin from which it is now being pumped (Shelton and others, 2001; Dawson and others, 2003). The discovery of solvents in water supplies in the 1980s prompted development of Federal MCLs for solvents and cleanup efforts (U.S. Environmental Protection A gency, 2012). A gencies responsible for stewardship of groundwater resources in the basin have extensive treatment programs to remove solvents from drinking-water supplies before delivery to consumers (Water Replenishment District of Southern California, 2012).

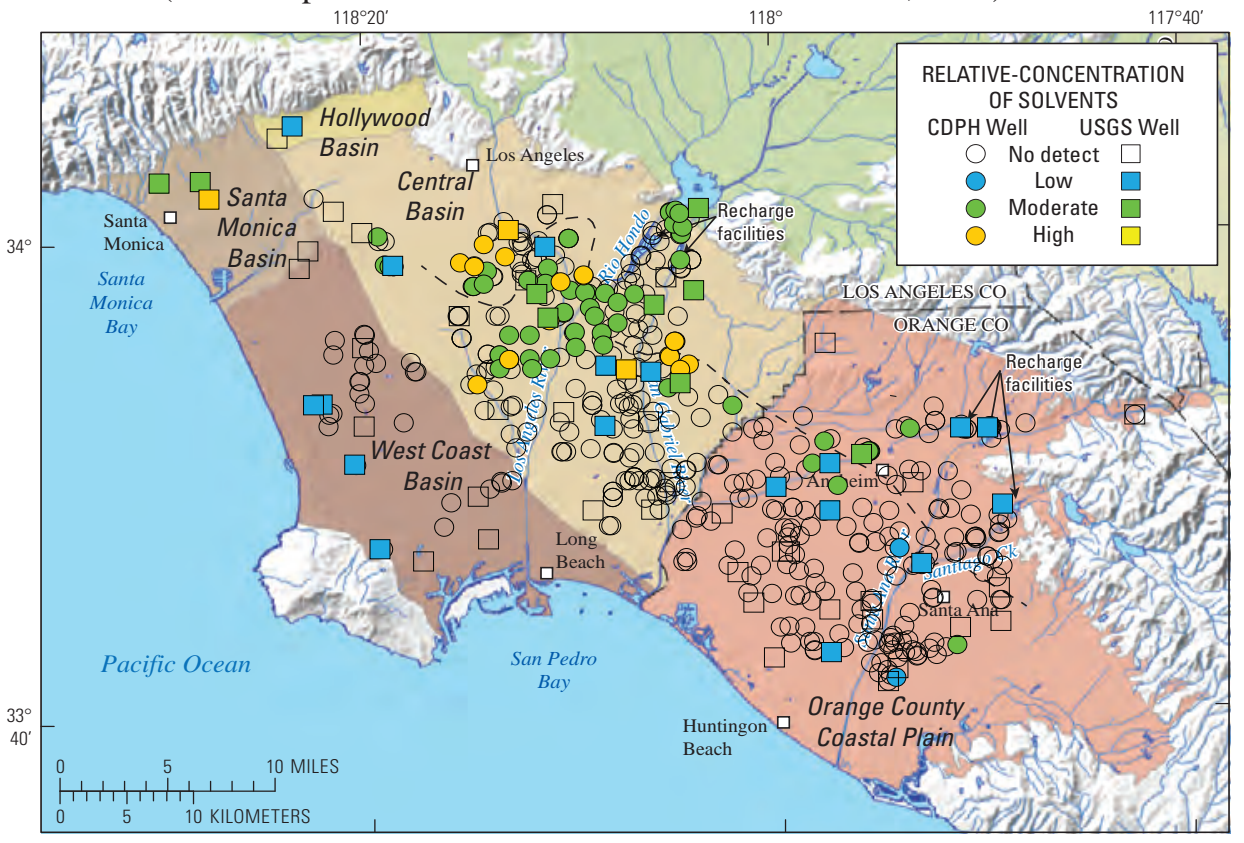

By M iranda S. Fram and K enneth Belitz

\section{SELECTED REFERENCES}

California Department of Water Resources, 2003, California's groundwater: California Department of Water Resources Bulletin 118, 246 p.

Dawson, B.J.M ., B elitz, K enneth, Land, M ichael, and Danskin, W.R., 2003, Stable isotopes and volatile organic compounds along seven ground-water flow paths in divergent and convergent flow systems, Southern California, 2000: U.S. Geological Survey Water-Resources Investigations Report 03-4059, 79 p.

Goldrath, Dara, Fram, M .S., L and, M ichael, and B elitz, K enneth, 2012, Status of groundwater quality in the Coastal L os A ngeles Basin, 2006-California GA M A Priority B asin Project: U.S. Geological Survey Scientific Investigations Report 2012-5048, 62 p. (A Iso available at http://pubs.usgs.gov/sir/2012/5048/.)

Shelton, J.L., Burow, K.R., B elitz, K enneth, Dubrovsky, N.M ., L and, M ichael, and Gronberg, J.A., 2001, L ow-level volatile organic compounds in active public supply wells as ground-water tracers in the Los A ngeles physiographic basin, California, 2000: U.S. Geological Survey Water-Resources Investigations Report 01-4188, 29 p.

U.S. Environmental Protection A gency, 2012, Safe Drinking Water A ct (SDWA), accessed M arch 2012 at http://water.epa.gov/lawsregs/rulesregs/sdwa/.

Water Replenishment District of Southern California, accessed M arch 2012 at http://www.wrd.org

\section{Priority Basin Assessments}

GAM A's Priority Basin Project $(P B P)$ assesses water quality in the part of the aquifer systems used for drinking water, primarily public supply. Water quality in shallower and deeper parts may differ from that in the primary aquifer system. GA M A's D omestic Well Project assesses water quality in the shallower parts of the aquifer systems. Ongoing assessments are being conducted in more than 120 basins throughout California.

The PBP assessments are based on a comparison of constituent concentrations in untreated groundwater with benchmarks established for the protection of human health and for aesthetic concerns. The PB P does not evaluate the quality of drinking water delivered to consumers.

The PBP uses two scientific approaches for assessing groundwater quality. The first approach uses a network of wells to statistically assess the status of groundwater quality. The second approach combines waterquality, hydrologic, geographic, and other data to hel $p$ assess the factors that affect water quality. In the Coastal LoS A ngeles $B$ asin study unit, data were collected by the PBP in 2006 and from the CDPH database for 2003-2006. The PBP includes chemical analyses not generally available as part of regulatory compliance monitoring, including measurements at concentrations much lower than human-health benchmarks and measurement of constituents that can be used to trace the sources and movement of groundwater.

\section{For more information}

Technical reports and hydrologic data collected for the GA M A Program may be obtained from

\section{GAMA Project Chief}

U.S. Geological Survey

California Water Science Center

4165 Spruance R oad, Suite 200

San Diego, CA 92101

Telephone number: (619) 225-6100

WEB: http://ca.water.usgs.gov/gama

\section{GAMA Program Unit}

State Water R esources Control B oard

Division of Water Quality

PO B ox 2231, Sacramento, CA 95812

Telephone number: (916) 341-5779

WEB: http://www.waterboards.ca.gov/ water_issues/programs/gama 